\title{
Soil moisture impacts on convective indices and precipitation over complex terrain
}

\author{
Christian Barthlott $^{1 *}$, Christian Hauck ${ }^{1,2}$, Gerd SCHÄDler $^{1}$, Norbert KalthofF ${ }^{1}$ and \\ CHRISTOPH KOTTMEIER ${ }^{1}$
}

${ }^{1}$ Institute for Meteorology and Climate Research, Karlsruhe Institute of Technology (KIT), Karlsruhe, Germany

${ }^{2}$ Department of Geosciences, University of Fribourg, Switzerland

\begin{abstract}
The impact of soil moisture on convective precipitation, convective indices, surface energy balance components, and near-surface meteorological variables is analysed for seven intensive observation periods of the Convective and Orographically induced Precipitation Study (COPS) conducted in summer 2007 using a non-hydrostatic limited-area atmospheric prediction model. The control runs are compared to sensitivity experiments under dry $(-25 \%)$ and wet $(+25 \%)$ initial soil moisture conditions. In the wet experiment, surface fluxes produce moister and cooler boundary layers with increased equivalent potential temperatures. Furthermore, the lifting condensation level and the level of free convection are lowered for all analysed regions, even under different synoptic controls. The comparison of boundary-layer and mid-tropospheric forcing regimes reveal that the impact of soil moisture on the atmosphere is not systematically higher for boundary-layer forcing. Whereas the Bowen ratio exhibits a clear dependence on soil moisture conditions, the impact on precipitation is complex and strongly depends on convective inhibition. A considerable, but non-systematic dependence of convective precipitation on soil moisture exists in the analysed complex orography. The results demonstrate the high sensitivity of numerical weather prediction to initial soil moisture fields.
\end{abstract}

\section{Zusammenfassung}

Der Einfluss von Bodenfeuchte auf konvektiven Niederschlag, Konvektionsindices, Energiebilanzkomponenten und bodennahe meteorologische Variablen wird für sieben Intensivmesstage von COPS (Convective and Orographically induced Precipitation Study, Sommer 2007) mit einem nicht-hydrostatischen atmosphärischen Vorhersagemodell untersucht. Sensitivitätsstudien mit trockenerem $(-25 \%)$ und feuchterem $(+25 \%)$ Boden im Vergleich zum Referenzlauf zeigen bei erhöhter Bodenfeuchte kühlere Temperaturen und eine erhöhte Feuchte in der atmosphärischen Grenzschicht mit einer erhöhten pseudopotentiellen Temperatur in Bodennähe. Das Hebungskondensationsniveau und das Niveau der freien Konvektion liegen in allen betrachteten Teilregionen auch bei unterschiedlichen synoptischen Lagen tiefer als im Referenzlauf. Des Weiteren zeigt sich, dass der Einfluss der Bodenfeuchte auf die Atmosphäre an Tagen mit schwachem synoptischem Antrieb nicht systematisch stärker ist als an Tagen mit starkem großskaligem Antrieb. Während für das Bowen-Verhältnis eine eindeutige Abhängigkeit von der Bodenfeuchte vorliegt, ist der Einfluss auf den konvektiven Niederschlag komplex und stark von der CIN (Konvektionsunterdrückung) beeinflusst. Für die hier analysierte Mittelgebirgsregion wird eine deutliche, aber nicht-systematische Abhängigkeit des simulierten Niederschlags von der Bodenfeuchte gefunden und damit die große Sensitivität der Modellergebnisse von den Bodenfeuchtefeldern aufgezeigt.

\section{Introduction}

Soil moisture is an important parameter in the soilatmosphere system, which influences the soil system's hydrology as well as the availability of humidity in the planetary boundary layer (PBL) through evaporative processes. PBL humidity is controlled mainly by the energy balance at the Earth's surface, large-scale advection, and advection on the mesoscale exhibiting a daily cycle. In situations with weak synoptic forcing, the PBL characteristics and their impacts on the triggering and/or dynamics of convective storms are

\footnotetext{
*Corresponding author: Christian Barthlott, Institute for Meteorology and Climate Research, Karlsruhe Institute of Technology (KIT), Hermannvon-Helmholtz-Platz 1, 76344 Eggenstein-Leopoldshafen, Germany, e-mail: christian.barthlott@kit.edu
}

strongly influenced by the partitioning of available radiation energy into sensible and latent heat, which in turn is determined by soil moisture. Previous observational and modelling studies demonstrated that soil moisture strongly contributes to the variability of surface temperature and precipitation via the exchange of water and energy between the land surface and the atmosphere (e. g. KOSTER et al., 2000). As was stated by DAI et al. (1999), soil moisture may decrease the daily temperature range by increasing daytime surface evaporative cooling. Furthermore, mesoscale circulations generated by land-surface wetness inhomogeneities often have a stronger impact than turbulent fluxes on the formation of clouds and subsequent precipitation (e.g., SCHÄDLER, 1990; CHEN and AVISSAR, 1994; TAYLOR et al., 2007). These circulations are generated by surface sensible heat flux gradients, which result from spatial 
variations in surface evapotranspiration, solar irradiance reflection/absorption, and thermal energy storage in the soil (Cheng and CotTon, 2004).

Given the importance of land-atmosphere feedback for improving short- and long-term weather prediction, it is essential to have a clear understanding of the processes involved, as well as of their spatial and temporal variability (KOSTER et al., 2003). Previous studies showed contradictory results for the existence and sign of feedback, which may vary spatially and temporally. According to the theory of the soil moisture-rainfall feedback described by PAL and ElTAHIR (2001), wet soil conditions lead to an increase in the PBL's total energy (described by the moist static energy). This increase is expected to result in an increase in the convective available potential energy (CAPE). Regional climate simulations on the continental scale reveal that higher values of soil moisture lead to an enhanced amount of evapotranspiration, which is supposed to be indirectly responsible for more intense convective rainfall ( $\mathrm{SCH} \mathrm{Ä} \mathrm{R}$ et al., 1999). It is assumed that a positive feedback mechanism between initial soil moisture and future rainfall exists: wet soils are associated with the buildup of shallow boundary layers with high values of low-level entropy by concentrating the supply of heat and moisture by the surface fluxes into a comparatively small volume of air (SCḦ̈R et al., 1999; PAL and ELTAHIR, 2001). This mechanism represents a source of convective instability. FINDELL and ELTAHIR (2003) used a 1D PBL model to analyse the impact of soil saturation on PBL development and the triggering of convection in different atmospheric settings. They found on average a positive feedback between soil moisture and rainfall over Illinois but demonstrated that, depending on the atmospheric conditions, both positive and negative feedbacks can be sustained. Furthermore, PAN et al. (1996) found that in a humid atmosphere, an increase in soil moisture decreased the rainfall due to insufficient thermal forcing to initiate convection. Rainfall was enhanced when the lower atmosphere was thermally unstable and relatively dry. Using a coupled one-dimensional land surface-PBL model, EK and HOLTSLAG (2004) showed that decreasing soil moisture may actually lead to an increase in PBL clouds in some cases.

Whereas the above statements are valid for flat terrain, the influence of soil moisture on convective indices and precipitation over complex terrain has been investigated so far by few authors only. For example HOHENEGGER et al. (2009) investigated the soil moisture-precipitation feedback over the Alpine region by simulations with resolved and parameterised convection for one full month. The two systems did not only yield different strengths of feedback, but also different signs. The different feedback signs were found to be related to the presence of a stable layer on top of the PBL. Dry initial soil moisture conditions with $2.2 \mathrm{~km}$ grid spacing yield more vigorous thermals which can break through the stable air bar-

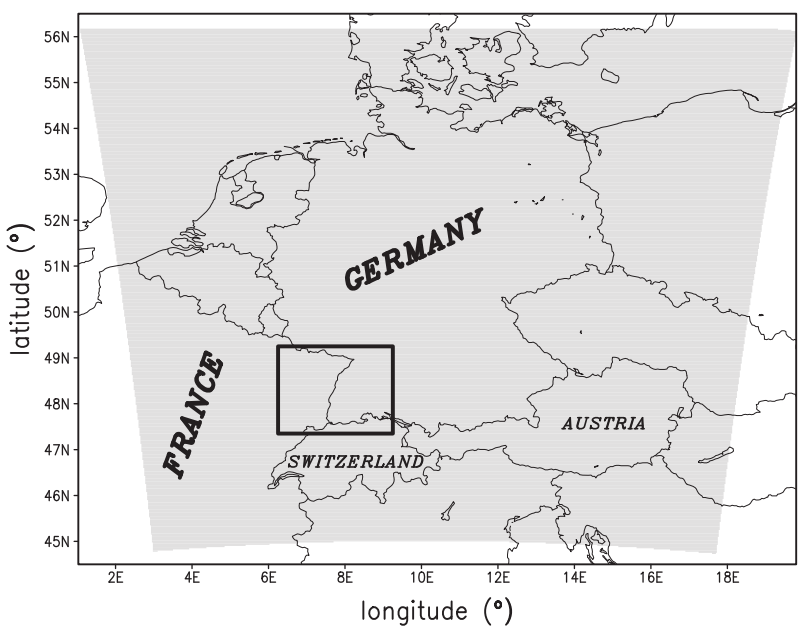

Figure 1: COSMO simulation area (grey), including the COPS domain (black rectangle).

rier more easily, thus leading to a negative soil moistureprecipitation feedback (HOHENEGGER et al., 2009).

Initial observations using a newly installed soil moisture network (SOMONET, Karlsruhe Institute of Technology, KRAUSS et al., 2010) in the region of a low mountain range (Black Forest in southwestern Germany) show that simulated and measured soil moisture values may differ strongly (HAUCK et al., 2011). The mean bias for most of the stations and measurement depths lies around 20-30\%. As a consequence, the simulated turbulent fluxes and boundary-layer characteristics differ from the measured ones. It is expected that under weak synoptic forcing the impact of soil moisture on near-surface variables and PBL characteristics is larger than for strong synoptic forcing. This hypothesis will be investigated here by analysing different types of convection forcing in orographically structured terrain. In addition, the undetermined feedback between initial soil moisture and convective processes mentioned earlier will be examined. The specific questions addressed in this study are:

1. How important is soil moisture to the amount of convective precipitation over complex terrain?

2. To what an extent does soil moisture influence energy balance components and near-surface meteorological variables like temperature and humidity over complex terrain?

3. How are convective indices affected by different soil moisture contents over complex terrain?

4. Does the influence of soil moisture on convective precipitation depend more on the type of synoptic controls (i. e. weak or strong synoptic forcing) or the individual terrain structure (mountain or valley)? 
Table 1: Hydraulic parameters of the different soil types (DoMs et al., 2007).

\begin{tabular}{|c|c|c|c|c|c|c|}
\hline soil type & $\begin{array}{l}3 \\
\text { sand }\end{array}$ & $\begin{array}{l}4 \\
\text { sandy } \\
\text { loam }\end{array}$ & $\begin{array}{l}5 \\
\text { loam }\end{array}$ & $\begin{array}{l}6 \\
\text { loamy } \\
\text { clay }\end{array}$ & $\begin{array}{l}7 \\
\text { clay }\end{array}$ & $\begin{array}{l}8 \\
\text { peat }\end{array}$ \\
\hline volume of voids & 0.364 & 0.445 & 0.455 & 0.475 & 0.507 & 0.863 \\
\hline field capacity & 0.196 & 0.260 & 0.340 & 0.370 & 0.463 & 0.763 \\
\hline permanent wilting point & 0.042 & 0.100 & 0.110 & 0.185 & 0.257 & 0.265 \\
\hline
\end{tabular}

Table 2: Selected COPS IOPs with area-averaged initial volumetric water content (VWC in \%) of the uppermost layer $(0-1 \mathrm{~cm})$ of each reference run sorted by the predominating forcing mechanism.

\begin{tabular}{rllllll}
\hline IOP & date & type & $\begin{array}{l}\text { VWC } \\
\text { COPS }\end{array}$ & $\begin{array}{l}\text { VWC } \\
\text { Vosges }\end{array}$ & $\begin{array}{l}\text { VWC } \\
\text { Rhine valley }\end{array}$ & $\begin{array}{l}\text { VWC } \\
\text { Black Forest }\end{array}$ \\
\hline 8b & 15 July 2007 & I & 25.5 & 21.4 & 27.3 & 27.4 \\
15a & 12 August 2007 & I & 32.8 & 30.3 & 35.7 & 34.5 \\
9c & 20 July 2007 & II & 26.1 & 24.6 & 27.4 & 27.3 \\
14a & 6 August 2007 & II & 24.9 & 21.6 & 25.9 & 27.2 \\
3a & 14 June 2007 & III & 27.3 & 22.9 & 28.7 & 31.0 \\
4b & 20 June 2007 & III & 27.5 & 24.2 & 29.2 & 28.6 \\
15b & 13 August 2007 & III & 31.6 & 29.5 & 35.6 & 32.1 \\
\hline
\end{tabular}

\section{Method}

To simulate the impact of soil moisture on convective indices and precipitation, the non-hydrostatic limited-area atmospheric prediction model COSMO (COnsortium for Small-scale MOdeling, SCHÄTTLER et al., 2009) is used. The model employs an Arakawa C-grid for horizontal differencing on a rotated latitude/longitude grid. We use model version 4.0 in the standard configuration used by the German Weather Service with a grid spacing of $2.8 \mathrm{~km}$ and 50 vertical layers, which allows for turning off the parameterisation of deep convection. Shallow convection is parameterised using a modified Tiedtke scheme. The model uses a six-class scheme, including graupel for microphysics, a turbulent kinetic energy (TKE) scheme for turbulence, and a two-time level Runge-Kutta method for the dynamics. The surface fluxes of momentum, heat, and moisture provide for the coupling between the atmospheric part of the model and the multi-layer soil model TERRA-ML. A TKE-based surface transfer scheme for the transport through the surface layer is used (SCH ̈̈TTLER et al., 2009). Most parameters of the soil model (heat capacity, water storage capacity, etc.) strongly depend on soil texture (Table 1).

Five different soil types are distinguished: sand, sandy loam, loam, loamy clay, and clay. Ice, rock and peat are incorporated additionally; hydrological processes in the ground are not considered for ice and rock. Soil and the atmosphere are coupled by precipitation and by the formation of dew and rime as a source of water as well as by evaporation and transpiration as a sink of water for the soil. The loss of soil water by runoff is taken into account as an additional sink. Exchange and transport of water between the stores is assumed to occur via infiltration, percolation, and capillary movement as well as by melting of snow and by freezing of water in the interception reservoir (Doms et al., 2007). Initial and

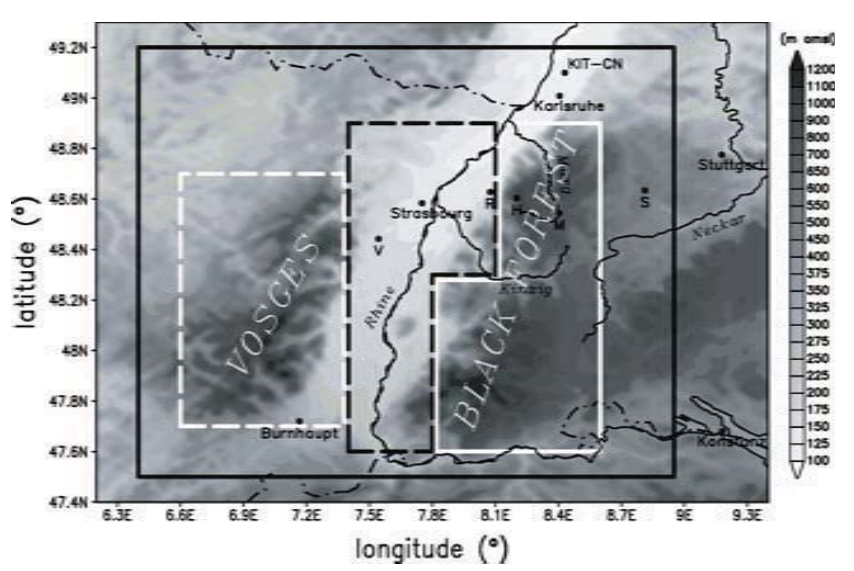

Figure 2: The COPS domain with supersites V, R, H, M, S (see text for abbreviations) and division into four boxes: COPS domain (black rectangle), Vosges mountains (white, dashed), Rhine valley (black, dashed), Black Forest (white, solid). Northern and Southern Black Forest are separated by the Kinzig valley.

hourly boundary data come from the COSMO-EU forecast of the German Weather Service $(7 \mathrm{~km}$ grid spacing), the initial time was 0000 UTC for all model runs. All simulations were run over a forecast time of $24 \mathrm{~h}$. Besides Germany, Switzerland, and Austria, the simulation domain (Fig. 1) contains smaller parts of neighbouring countries covering an area of $\sim 1300 \times 1200 \mathrm{~km}^{2}$ ( $421 \times 461$ grid points).

To examine the impacts of varying soil moisture on convective precipitation and convection-related parameters over complex and heterogeneous terrain, a model sensitivity study was performed with the COSMO model. The evaluation of possible forecast improvements with a more realistic (i. e. closer to observations) soil moisture initialisation is beyond the scope of this study. Seven intensive observation periods (IOPs) of 


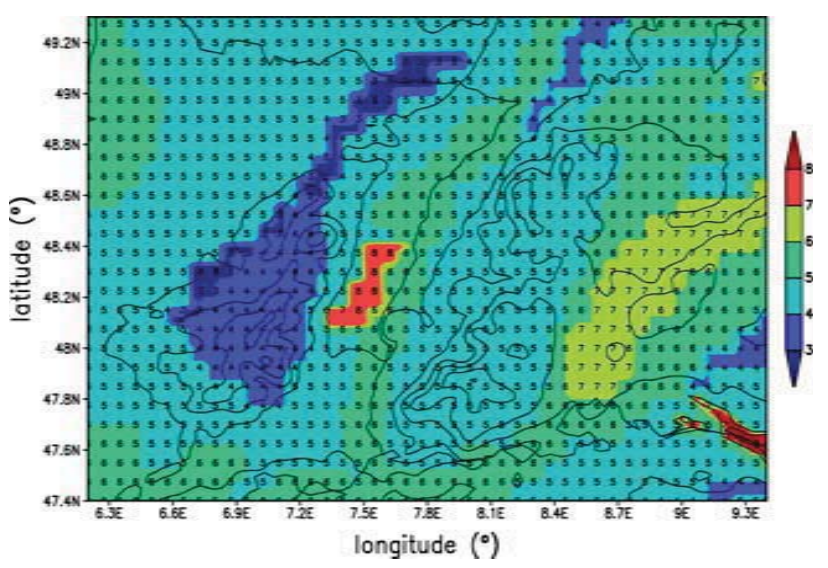

Figure 3: COSMO soil types (colour code and numbers - 3: sand, 4: sandy loam, 5: loam, 6: loamy clay, 7: clay, 8: peat, $>$ 8: water) for the COPS domain. Black isolines indicate orography.

the Convective and Orographicallyinduced Precipitation Study (COPS) were selected. The COPS international field campaign took place in southwestern Germany and eastern France in summer 2007 (Fig. 2). The overall goal of COPS was to advance the quality of forecasts of orographically induced convective precipitation by fourdimensional observations and modelling of its life cycle (WULFMEYER et al., 2008; KOTTMEIER et al., 2008). Five supersites with a large number of different observation systems were deployed along a transect through the COPS region, named V (Vosges), R (Rhine valley), $\mathrm{H}$ (Hornisgrinde), M (Murg valley), and S (Deckenpfronn near Stuttgart). Two additional radiosonde stations at the Karlsruhe Institute of Technology, Campus North (KIT$\mathrm{CN}$ ) and Burnhaupt le Bas provided information about the vertical structure of the atmosphere at the northern and southern borders of the COPS region (Fig. 2).

At first, a reference run (hereafter referred to as REF) was performed with unchanged soil moisture values coming from the $7 \mathrm{~km}$ COSMO-EU forecast for a selection of seven COPS IOPs (Table 2). Apart from the reference run, sensitivity experiments with dry $(-25 \%$, hereafter referred to as RED) and wet (+25\%, hereafter referred to as INC) initial soil moisture were conducted. The value of $25 \%$ was selected, because the mean bias between soil moisture observations and operational COSMO model values during COPS lies between 20-30\% in the area of interest (HAUCK et al., 2011; see Section 1). When choosing a soil moisture variation of $\pm 25 \%$ instead of using the full range from wilting point to field capacity, the values are still close to reality and extreme, nonsensical results can be excluded. Note that this modification was not done by subtracting or adding $25 \%$ volumetric water content (VWC in \%), but by multiplying the initial soil moisture values of the reference run by 0.75 and 1.25 , respectively. The change in soil moisture is applied to the entire model domain indicated in Fig. 1 and to all soil model levels. This keeps mesoscale disturbances that may develop in tight soil

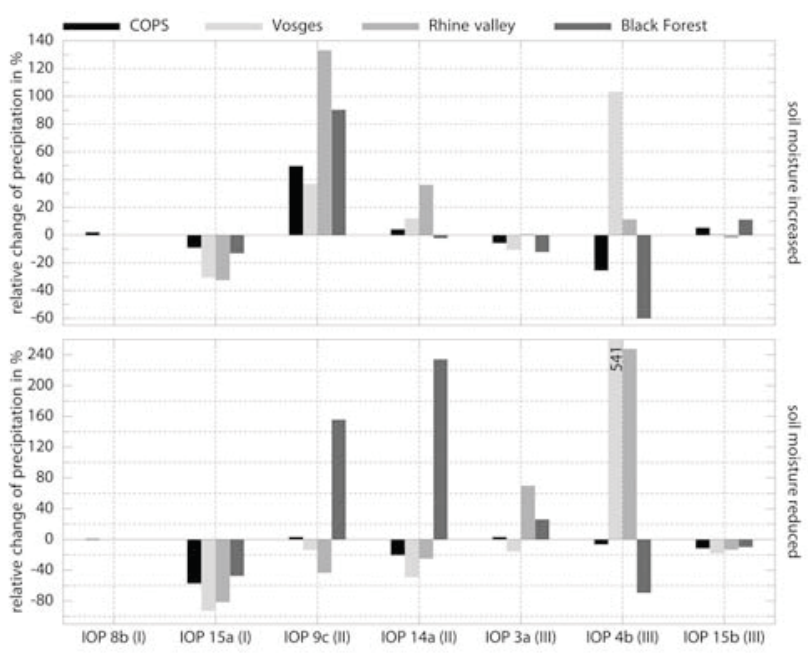

Figure 4: Relative change of the 24-h precipitation sum compared to the reference run for the wet (top) and dry (bottom) experiments. The respective forcing mechanism in each IOP is given in brackets.

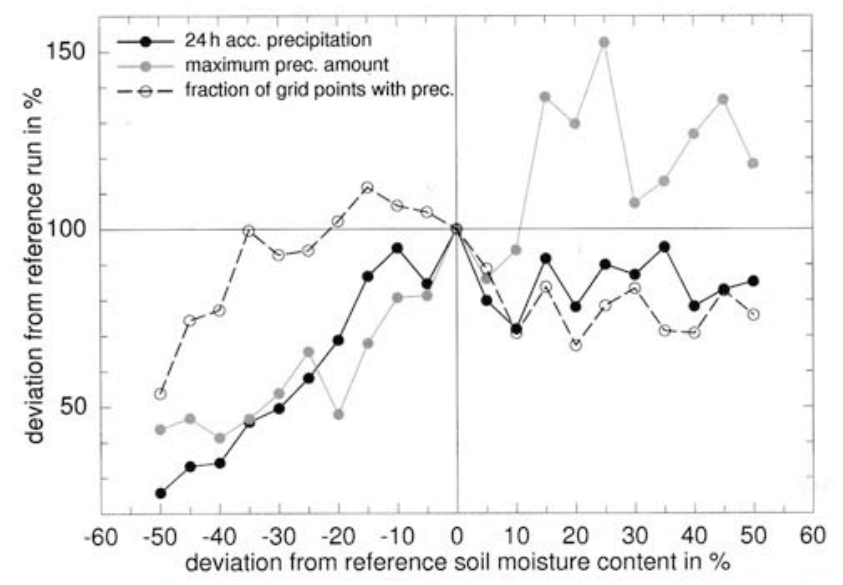

Figure 5: Deviations from the reference run as a function of different initial soil moisture contents for the COPS domain during IOP 15a.

moisture gradient belts outside of the area of interest. In addition, none of the modified soil moisture values reached the saturation or wilting point of the respective soil type when subtracting or adding $25 \%$ VWC.

The selected days were classified by the forcing mechanism predominating the triggering of convective precipitation (see KoTTMEIER et al., 2008): boundary-layer forcing (type I: airmass convection), mid- and uppertropospheric forcing (type II: convection triggered by synoptic-scale phenomena like fronts or pre-frontal convergence zones), or a combination of both (type III, Table 2). In order to detect possible regional differences in the response to soil moisture variations, four boxes were selected for the analysis (Fig. 2): (i) whole COPS domain, (ii) Vosges mountains, (iii) Rhine valley, and (iv) Black Forest. Soil hydraulic parameters and, as a consequence, the terrestrial hydrological cycle, depend strongly on the soil type and soil database used (ÁCS 
et al., 2010). The soil types in the COSMO model with the standard TERRA subsurface module (Fig. 3) show mainly sandy loam (class 4) in the Vosges mountains, loamy clay in the Rhine valley (class 6), and loam in the Black Forest (class 5).

For the whole COPS domain, several convective indices such as CAPE, convective inhibition (CIN), and the lifted index were calculated in steps of $30 \mathrm{~min}$. Recent findings by BARTHLOTT et al. $(2011,2010)$ show that in combination with a trigger mechanism, such as orographic lifting or lifting by convergence lines, CAPE and CIN can be suitable indicators of convective precipitation over complex terrain. CAPE and CIN were computed by lifting a parcel that reflects the mean values of the temperature and moisture in the lowest $50 \mathrm{hPa}$, whereas the lifted index is surface-based (SLI). Additionally, the lifting condensation level (LCL) and the level of free convection (LFC) were determined.

\section{Results}

\subsection{Sensitivity of precipitation to soil moisture}

In a first step, the 24-h precipitation sum of all grid points in the different control areas is analysed (Table 3). Besides IOP 8b, simulating hardly any precipitation, the increase or decrease of soil moisture by $25 \%$ does not influence the occurrence of precipitation itself. In all control areas, precipitation is either intensified or weakened, but the soil moisture variations of this magnitude do not lead to an absence of precipitation. The amount of increase or decrease in precipitation can reach large values, e.g. the largest increase for the COPS domain is $11221 \mathrm{l}$ (IOP 9c). Our study aims at identifying the soil-atmosphere feedback mechanisms and not the possible forecast improvements. For this reason, observed precipitation is not included in Table 3. Note that not all simulated precipitation is convective like on the days with strong synoptic forcing. However, a distinction between stratiform and convective precipitation is beyond the scope of the present study.

The soil moisture impact is also reflected by the relative change of precipitation (Fig. 4). However, none of the control areas exhibits fixed relationships between precipitation and soil moisture when comparing all sensitivity experiments. Even with similar forcing mechanisms, there is no systematic response to soil moisture. An important result of this study is that even under strong synoptic forcing, the impact of soil moisture on precipitation can be quite strong. For example, the reduction of soil moisture in IOP 14a leads to a relative increase of precipitation in the Black Forest of $243 \%$ (+1350 1).

Another finding resulting from Fig. 4 is that both the increase and reduction of soil moisture can lead to a lower precipitation amount (IOP 15a, PBL forcing). This implies that the reference soil moisture field of this day probably acts as an upper threshold value and further increase (from $33 \%$ to $41 \%$ mean soil moisture within the COPS area) or decrease (from $33 \%$ to $25 \%$ ) inhibits convective activity. With a mean volumetric water content of $33 \%$, the day under review exhibits the maximum soil moisture of all analysed IOPs. These high values may have suppressed strong rainfall due to insufficient thermal forcing for convection initiation. In order to analyse this phenomenon in more detail, additional sensitivity studies were performed for this day with the soil moisture being varied in steps of $5 \%$ from $-50 \%$ to $+50 \%$. Due to the high computation expenditure, these 21 different simulations in total cannot be performed for all IOPs analysed in this study. As the soil moisture is restricted by saturation and wilting point, a negligibly small portion of grid points was adjusted by the model in the run with soil moisture increased by $50 \%$. Results show that the daily precipitation sum increases with the increase of initial soil moisture (Fig. 5). The maximum amount of precipitation is simulated in the reference run. Further increase of soil moisture leads to slightly lower precipitation amounts fluctuating at about $80-90 \%$ of the value of the reference run. The maximum precipitation amount in the COPS domain is reached for a grid point in the $+25 \%$ run. The overall trend shows a positive relationship of maximum precipitation to soil moisture up to the increase of $25 \%$. Higher soil moisture initialisations do not lead to a further systematic increase or decrease. The percentage coverage of the COPS domain by rain reaches its maximum at $15 \%$ soil moisture reduction. Higher soil moisture contents lead to less areas covered by precipitation. Despite the highest maximum precipitation amount at increased soil moisture, the lower percentage of areas with precipitation in total leads to a reduced accumulated precipitation.

In order to have a closer look at the regional variability of precipitation, the precipitation deviations of the wet and dry experiments from the reference run in the whole COPS domain are given in Fig. 6. The lowest absolute precipitation change due to soil moisture variations occurs in IOPs $15 \mathrm{a}$ and $15 \mathrm{~b}$ when the mean soil moisture contents are largest. It can therefore be concluded that if the soil already is fairly wet, the influence of an additional soil moisture increase is small (see also Fig. 5). In IOP $8 \mathrm{~b}$, the absolute change of precipitation also is very small for comparatively low mean soil moisture conditions. However, in both sensitivity studies of IOP 8b, this day did not show any deep convection due to the presence of high CIN values. Therefore, the statement above is still valid. The absence of a systematic impact of soil moisture on convective precipitation is also reflected by the fact that in all analysed IOPs, the increase or decrease in initial soil moisture always leads to the occurrence of regions with enhanced or reduced precipitation (Fig. 6). None of the precipitation fields exhibits a systematic response in the whole area of investigation. The spatial/temporal heterogeneity highlights the noisi- 

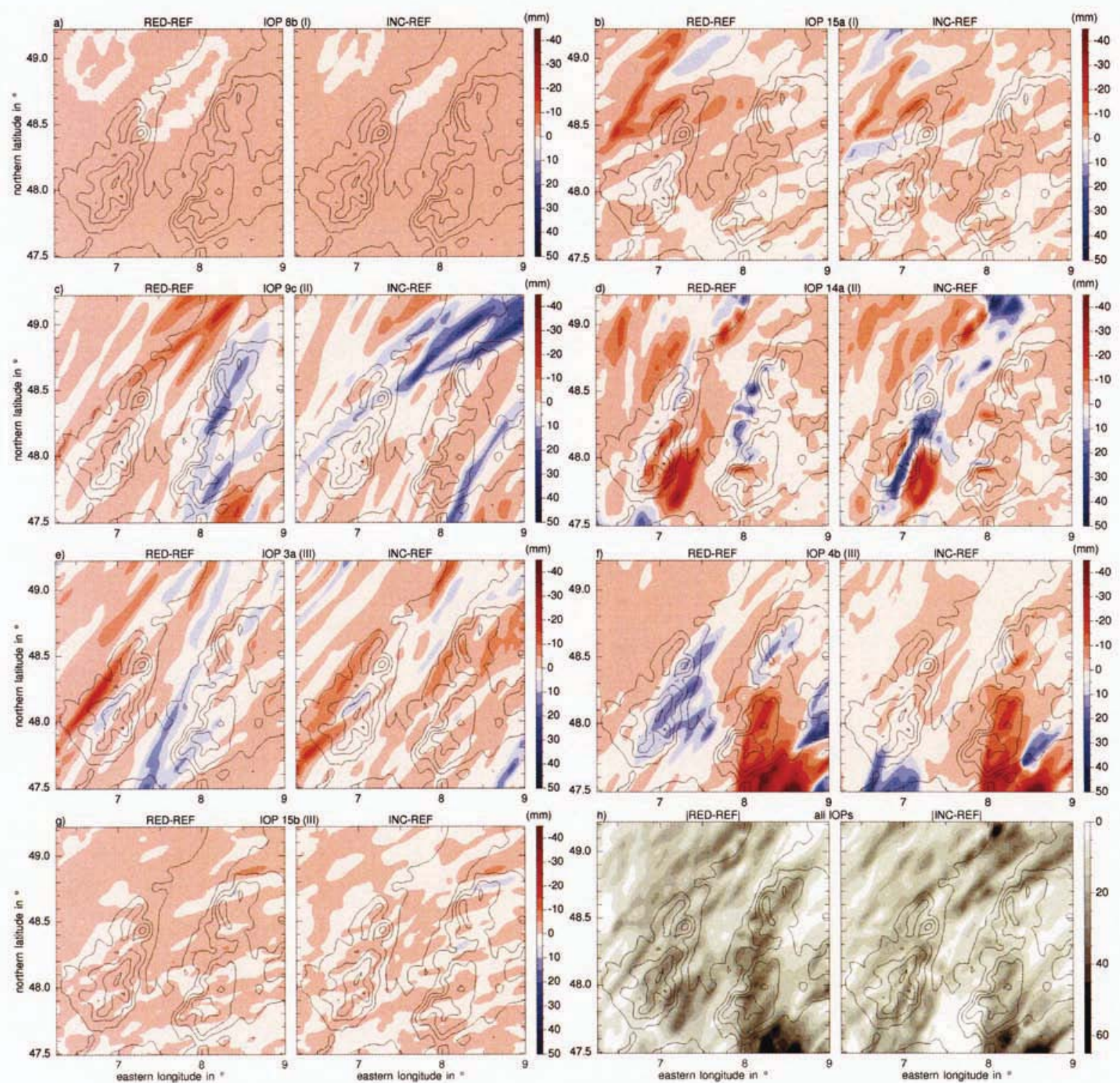

Figure 6: Precipitation deviation of the wet and dry experiments from the reference run for individual IOPs (a-g), and sum of absolute precipitation deviation for all IOPs (h) in $\mathrm{mm}$.

ness that is mainly related to the initiation and evolution of individual storms. Even after integrating over space and time (see Table 3), no systematic signal is detected. It is also found that for some specific locations, both the increase and decrease in initial soil moisture lead to a reduced amount of convective precipitation (northeastern Vosges in IOP 3a, southern part of the Black Forest and south of it in IOP $4 \mathrm{~b}$, southwestern Vosges/Rhine valley in IOP 14a), whereas no regions are found, where precipitation is always enhanced. Another finding evident from Fig. 6 is that soil moisture variations can determine whether a convective cell is initiated or not, as can be seen from precipitation changes by cell tracks during IOP 9c. In general, no dependence of the precipitation change on the model soil type (Fig. 3) can be observed. Although specific locations with large sensi- tivity to soil moisture variations exist during individual IOPs, the sum of the changes of all IOPs does not reflect any region with a considerably higher response to soil moisture (Fig. 6 h). Obviously, the orography does not play any key role on the days under investigation. Although only a comparatively small amount of IOPs was analysed in this study, the results show that soil moisture is a parameter which needs to be represented well in numerical weather prediction (NWP) models in the full model domain. Hence, widespread accurate soil moisture measurements and even assimilation of these data in state-of-the-art NWP models are needed. 
Table 3: Simulated precipitation sum in 1 for the four control areas and sensitivity to initial soil moisture conditions.

\begin{tabular}{|c|c|c|c|c|c|c|c|c|c|c|c|c|}
\hline \multirow[t]{2}{*}{ IOP } & \multicolumn{3}{|c|}{ COPS } & \multicolumn{3}{|c|}{ Vosges } & \multicolumn{3}{|c|}{ Rhine valley } & \multicolumn{3}{|c|}{ Black Forest } \\
\hline & RED & REF & INC & RED & REF & INC & RED & REF & INC & RED & REF & INC \\
\hline $8 \mathrm{~b}(\mathrm{I})$ & 1.2 & 1.1 & 1.2 & 0 & 0 & 0 & $\overline{0}$ & 0 & 0 & 0 & 0 & 0 \\
\hline $15 \mathrm{a}(\mathrm{I})$ & 2501 & 5863 & 5325 & 130 & 1807 & 1255 & 211 & 1136 & 768 & 255 & 484 & 421 \\
\hline 9c (II) & 3202 & 22499 & 33720 & 4422 & 5122 & 7008 & 1138 & 2013 & 4693 & 7035 & 2752 & 5236 \\
\hline $14 \mathrm{a}$ (II) & 797 & 17359 & 18088 & 3338 & 6549 & 7334 & 2075 & 2768 & 3768 & 1927 & 577 & 564 \\
\hline $3 \mathrm{a}$ (III) & 35388 & 34291 & 32308 & 7863 & 9322 & 8339 & 6775 & 3990 & 4011 & 9634 & 7640 & 6710 \\
\hline $4 \mathrm{~b}$ (III) & 12901 & 13787 & 10289 & 4365 & 681 & 1383 & 3800 & 1093 & 1216 & 2561 & 8346 & 3329 \\
\hline 15b (III) & 5847 & 6614 & 6964 & 694 & 847 & 853 & 1383 & 1594 & 1562 & 2962 & 3287 & 3654 \\
\hline
\end{tabular}

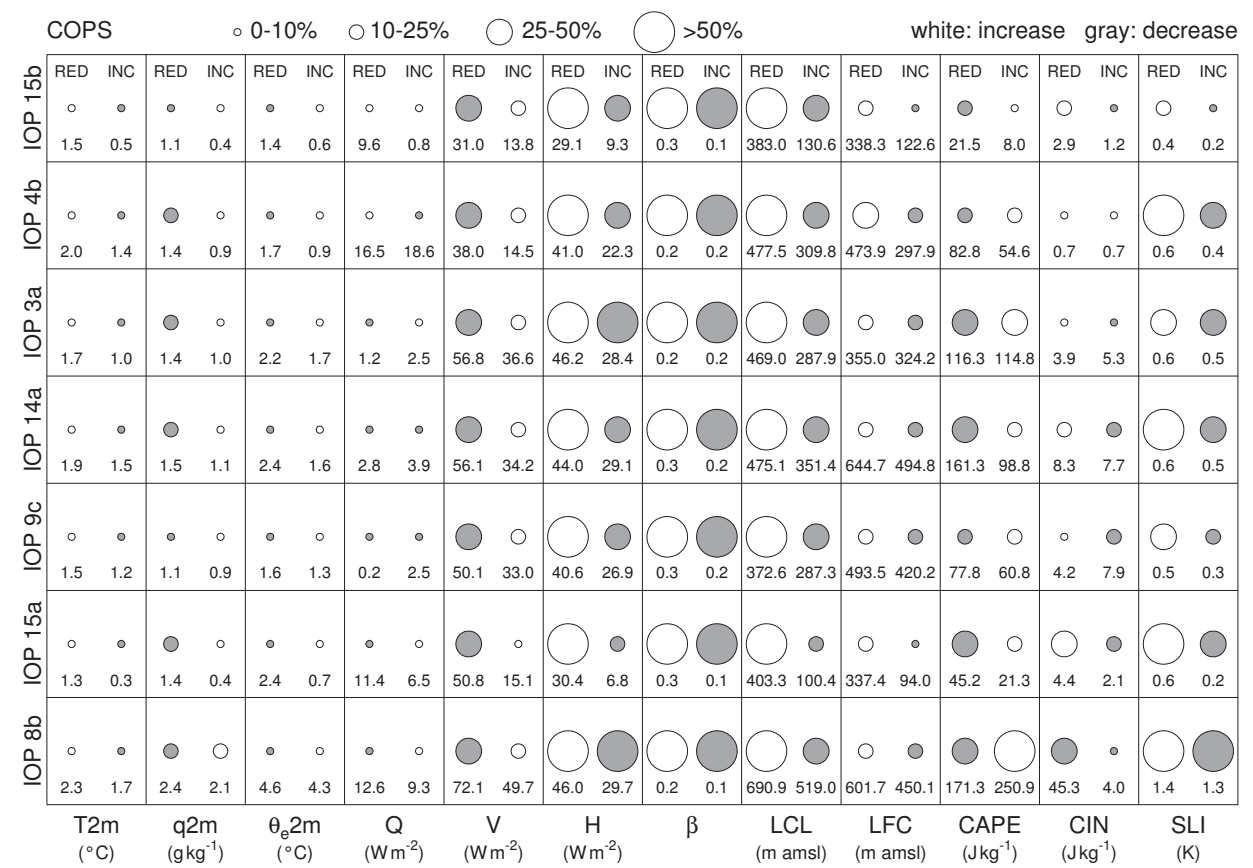

Figure 7: Change of mean parameters in the COPS domain. Each sector of the figure gives the relative change of the wet and dry experiments compared to the reference run in symbols and the absolute deviation of the mean value as a number beneath the symbols. Symbol size gives the amount of the rate of change in \%, white and grey denotes increase or decrease.

\subsection{Sensitivity of near-surface variables and convective indices}

The reasons for the lack of a systematic relationship between convective precipitation and soil moisture will now be addressed by analysing the sensitivity of nearsurface variables and convective indices. The focus will be put on mean values in the time period from 0800 to 2000 UTC. By concentrating on this period, the differences between the individual sensitivity experiments become more distinct. The said time period, however, is shorter than in the analysis of the 24-h precipitation sum of the previous section, because it is focussed on the conditions for the triggering of deep convection. The parameters analysed are the $2 \mathrm{~m}$ temperature $(\mathrm{T} 2 \mathrm{~m}), 2 \mathrm{~m}$ specific humidity (q2m), $2 \mathrm{~m}$ equivalent potential temperature $\left(\theta_{e}\right)$, surface net radiation $(\mathrm{Q})$, sensible heat flux $(\mathrm{H})$, latent heat flux $(\mathrm{V})$, Bowen ratio $\beta$, LCL, LFC, CAPE, CIN, and the SLI.
As expected, soil moisture exhibits a positive relationship to near-surface humidity and a negative relationship to near-surface temperature (Figs. 7-10) in agreement with e.g. DAI et al. (1999) and PAL and ELTAHIR (2001). This holds for all dominant forcing mechanisms and control areas. Mean temperature changes are always below $10 \%$, whereas humidity changes can reach values of 10-25\%. When soil moisture is increased, $\theta_{e}$ increases as well, except for the control area Black Forest in IOPs $4 \mathrm{~b}$ and 15b. Assuming that the conditions in the mid-troposphere remain insensitive to soil moisture variations, this leads to an enhanced potential instability by increasing the vertical gradient of $\theta_{e}$. The $\theta_{e}$ changes are always lower than $10 \%$. No systematic response to soil moisture variations is found for the net radiation Q, but rates of change are always smaller than $10 \%$ in all control areas (except for IOP 4b). Higher rates of change occur for the turbulent fluxes $\mathrm{H}$ and V. Again, with the exception of IOPs $4 \mathrm{~b}$ and $15 \mathrm{~b}$ in the Black Forest, the latent heat shows a 


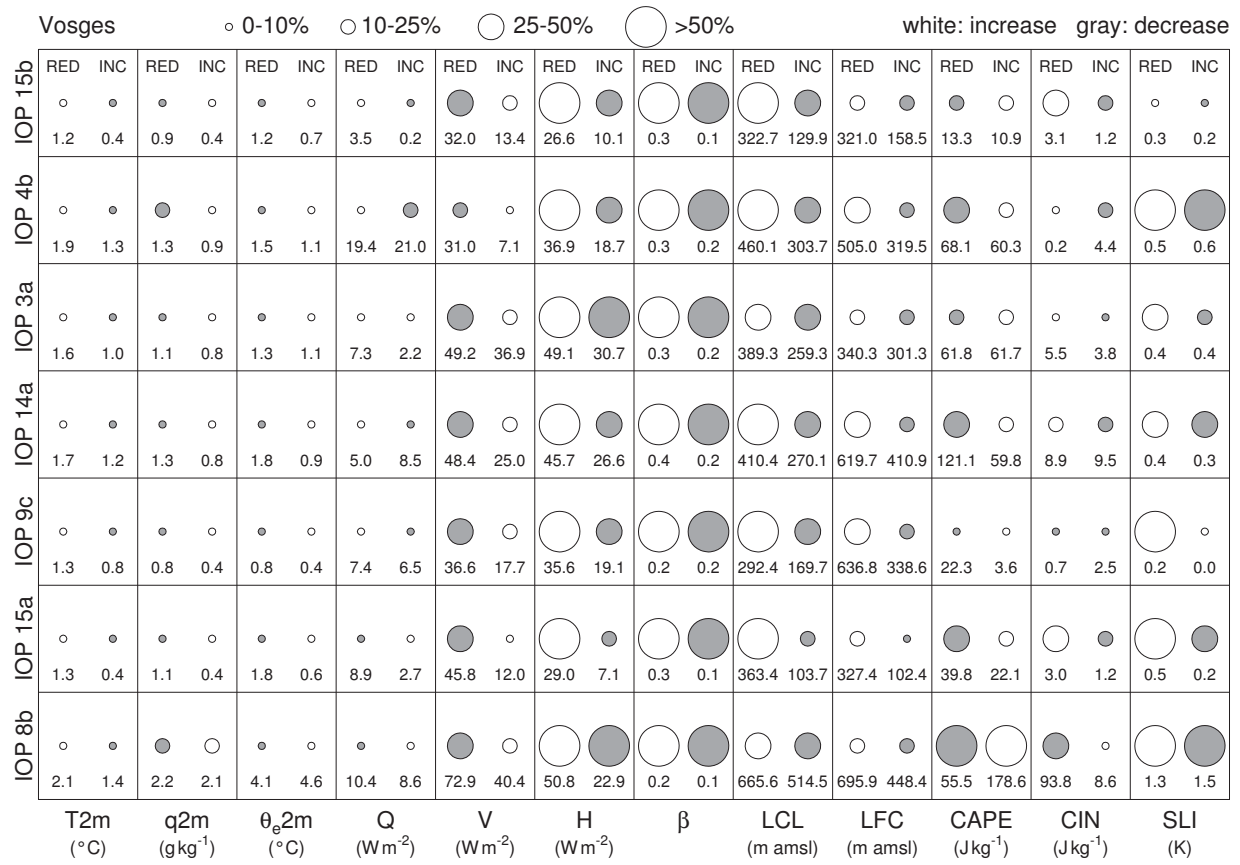

Figure 8: As Fig. 7, but for the Vosges area.

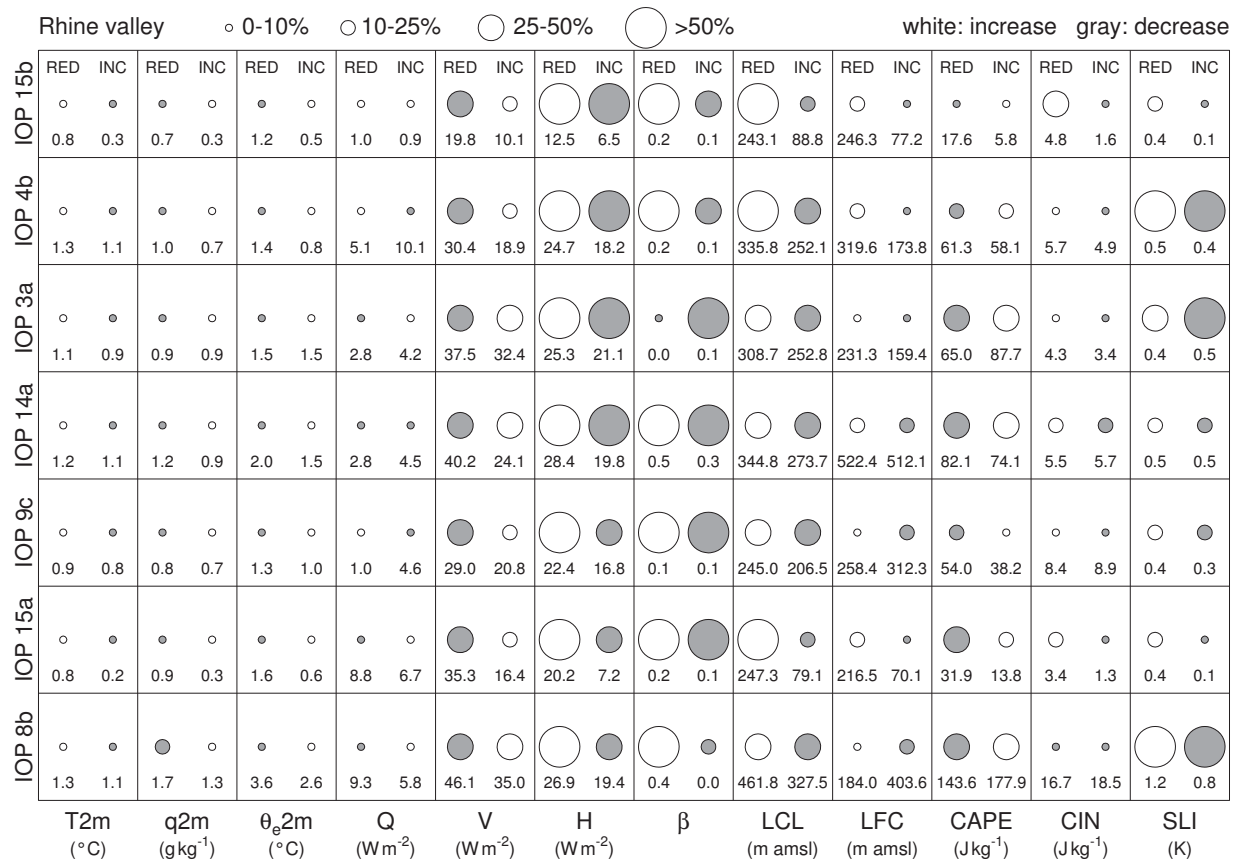

Figure 9: As Fig. 7, but for the Rhine valley.

positive relationship, whereas sensible heat shows a negative relationship to soil moisture. The COSMO model always simulates an increase in $\mathrm{H}$ by more than $50 \%$ in all control areas, when soil moisture is reduced by $25 \%$. The largest increase occurs during IOP $8 \mathrm{~b}$ in the Vosges mountains, where the mean sensible heat flux is raised by $51 \mathrm{~W} \mathrm{~m}^{-2}$. As a consequence of the heat flux changes, the Bowen ratio changed as well. Neglecting the small decrease of $\beta$ in the Rhine valley on IOP 3a, the Bowen ratio always exhibits a negative relationship to soil moisture. A reduced Bowen ratio indicates that more available radiation energy is transformed into latent heat and humidity is accumulated within the lower PBL. As expected, the surface fluxes produce moister, cooler, and more shallow boundary layers in the wet experiments than in the reference run and the dry experiment.

A higher soil moisture results in a smaller dew point depression by the reduced near-surface temperature and increased humidity. As a consequence, a decrease in 


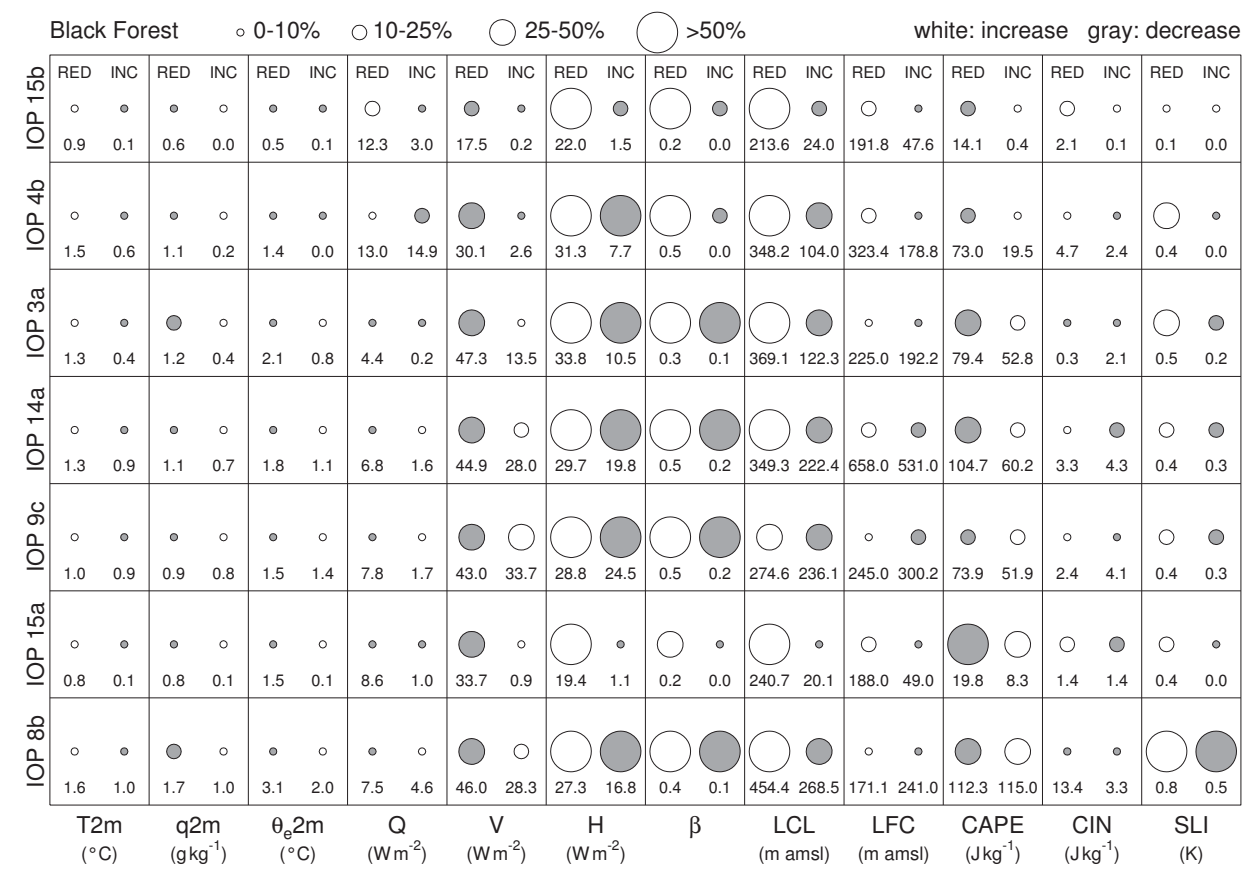

Figure 10: As Fig. 7, but for the Black Forest area.

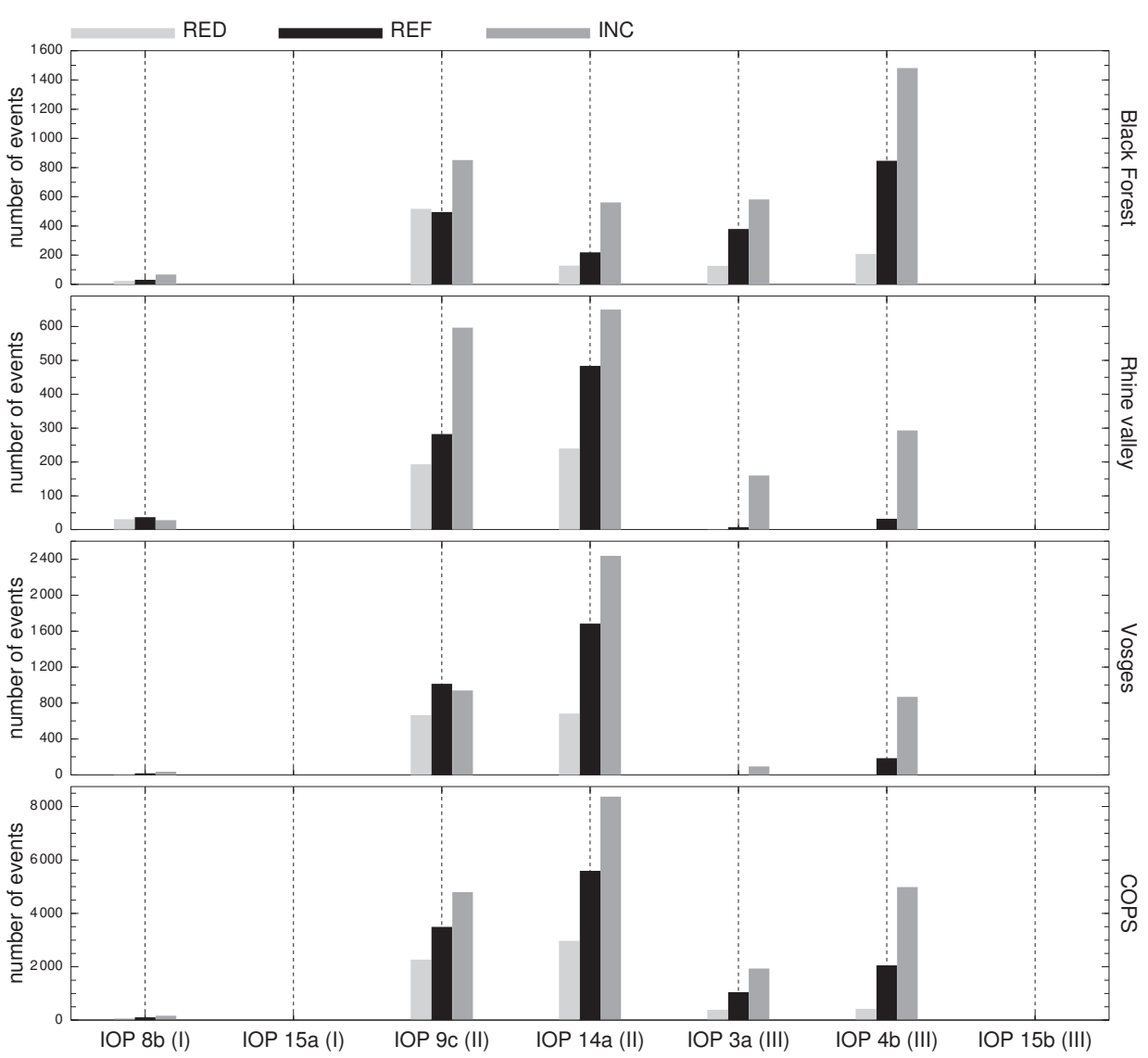

Figure 11: Number of grid points where CAPE $>800 \mathrm{~J} \mathrm{~kg}^{-1}$ and CIN $\leq 1 \mathrm{~J} \mathrm{~kg}^{-1}$ for the reference run and the wet and dry experiments of all IOPs. 

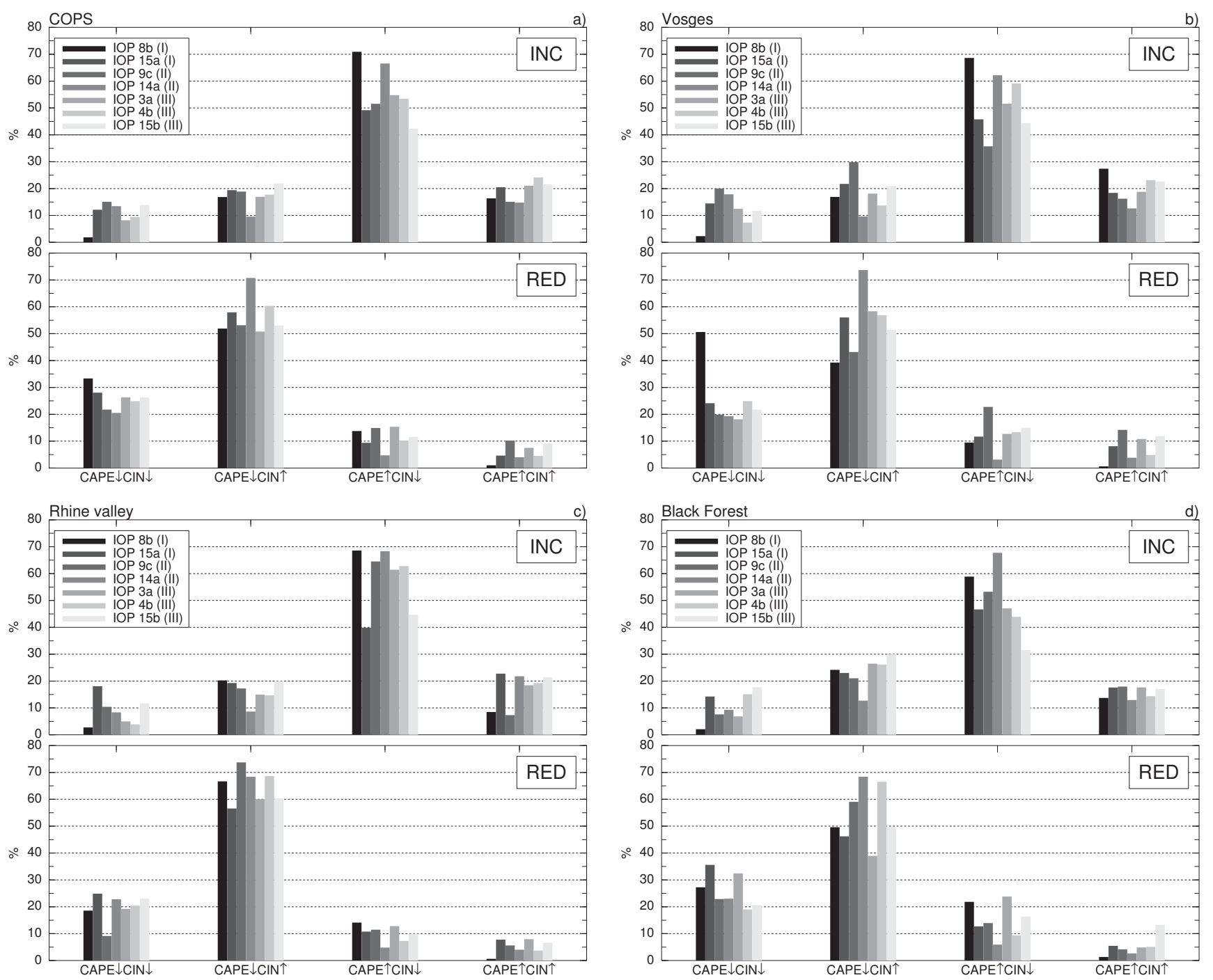

Figure 12: Percentage of grid points for the four possible combinations of CAPE and CIN variations of the wet and dry experiments in the control areas COPS (a), Vosges (b), Rhine valley (c), and Black Forest (d).

the height of the cloud base (Convective Condensation Level CCL, LCL) and the LFC is expected. The results show a negative relationship of LCL and LFC to soil moisture (i.e. they are lower in the wet experiment) for all control areas and all IOPs. This systematic behaviour reaches rates of change of up to $25-50 \%$ with a maximum absolute change for LFC of $696 \mathrm{~m}$ during IOP $8 \mathrm{~b}$ in the Vosges mountains. On the average, the LCL and LFC are lowered in the wet experiment in the COPS domain by values of 467 and $475 \mathrm{~m}$, respectively. In the dry experiment, the average increase of both quantities is similar (283 and $251 \mathrm{~m})$.

By lowering the CCL, deeper clouds and an increase in the magnitude of convective events can be expected (PAL and ELTAHIR, 2001), if the presence of an inversion at the PBL top does not suppress upward motion. Previous studies showed that a significant correlation between near-surface wet-bulb temperature and CAPE exists (WILliams and RENNO, 1993) and that the probability of occurrence of storms and the average storm rainfall increase linearly with the wet-bulb temperature (ELTAHIR and PAL, 1996). The effects of soil moisture on selected convective indices will be discussed in the following section.

For all IOPs and control areas, CAPE shows a positive relationship to soil moisture. When comparing the Vosges, Rhine valley, and the Black Forest, the largest gain/loss rates occur on days with PBL forcing (IOPs 8b, 15a). The largest deviation from the mean value of the reference run occurs in the COPS domain, where mean CAPE is increased (decreased) by 251 (171) $\mathrm{J} \mathrm{kg}^{-1}$ due to the increased (reduced) initial soil moisture during IOP $8 \mathrm{~b}$. The response of mean CIN values to soil moisture changes, however, is not systematic. For most of the analysed days and control areas, CIN is negatively related to soil moisture. For a number of cases, however, mean CIN is also reduced in the dry experiment (e.g. IOP 8b, COPS domain). This means that CIN is not only controlled by the boundary layer conditions, but to a certain extent by conditions and processes between the LCL 
and LFC, too. The analysis of individual grid point data instead of box averages shows that CAPE depends on near-surface $\theta_{\mathrm{e}}$, while the correlation of CIN with $\theta_{\mathrm{e}}$ is poor (not shown). These findings are in general agreement with recent findings by KALTHOFF et al. (2011) who analysed observational COPS data. The lack of a systematic relationship between CIN and soil moisture is supposed to be one of the reasons for the missing systematic relationship to precipitation (Fig. 4) when we assume that the areas with higher CIN suppress convective precipitation. The response of the lifted index (indicative of the severity of thunderstorms) to soil moisture variations again is more obvious. Despite small increases in SLI in the Vosges mountains during IOP 9c and in the Black Forest during IOP 15 b, all experiments show a negative relationship of SLI to soil moisture.

In general, the potential for the evolution of thunderstorms is enhanced when CAPE values are high and CIN is small. Hence, the occurrence of such optimal conditions and its response to soil moisture variations are of particular interest. For each sensitivity study, the number of grid points where CAPE $>800 \mathrm{~J} \mathrm{~kg}^{-1}$ and CIN $\leq$ $1 \mathrm{~J} \mathrm{~kg}^{-1}$ were counted for all control areas (Fig. 11). For most of the analysed days, the number of such events increases with increasing soil moisture, indicating a higher potential for thunderstorms in the wet experiment. The fact that this combination does not occur in IOPs 15a and $15 \mathrm{~b}$ can be explained by the comparably low CAPE values present on these days. Besides IOP $8 \mathrm{~b}$, these two days exhibit the lowest amount of precipitation of all IOPs analysed (Table 3). Regarding the whole COPS domain, all IOPs show an increasing number of specified CAPE-CIN combinations with soil moisture, whereas some of the subdomains (Black Forest IOP 9c, Vosges IOP 9c, Rhine valley IOP $8 b$ ) do not show this systematic relationship. Although a relationship between the specified CAPE-CIN combinations and soil moisture is found in the COPS domain, no systematic response of convective precipitation to soil moisture could be identified there. As was pointed out by GANTNER and KALTHOFF (2010), the soil moisture-atmosphere feedback may differ between the genesis and the modification of convective systems. A possible explanation of the missing relationship is that a trigger process is still needed to release the potential energy, even if the potential for thunderstorms is high. However, the impact of soil moisture on the existence or strength of such a trigger mechanism is not investigated in the present study.

For a more thorough investigation of the existence of any systematic behaviour of CAPE and CIN induced by soil moisture variations, the response of all grid points in the respective control area was allocated to one of the four possible combinations of changes compared to the reference run (" $\uparrow$ " and " $\downarrow$ " representing increase and decrease, respectively): CAPE $\downarrow / \mathrm{CIN} \downarrow$, $\mathrm{CAPE} \downarrow / \mathrm{CIN} \uparrow, \mathrm{CAPE} \uparrow / \mathrm{CIN} \downarrow$, and $\mathrm{CAPE} \uparrow / \mathrm{CIN} \uparrow$. The percentage of grid points allocated to into these four combinations for all control areas is given in Fig. 12. When soil moisture is increased, higher CAPE and reduced CIN values occur at most of the grid points. For the Vosges and Black Forest areas, however, the maxima are not always well pronounced, i. e. below $35 \%$. In these two control areas, the distribution of the combinations is dominated ( $>50 \%$ of the cases) in four (Vosges) and three (Black Forest) of seven IOPs only.

The distributions of the dry experiments have their maxima in the class with lower CAPE and higher CIN values with the exception of the Vosges mountains in IOP $8 \mathrm{~b}$, where the maximum is found in the class with both reduced CAPE and CIN. Although the mean behaviour for the whole COPS domain is in agreement with the general assumption of CAPE and CIN modification, the results show that when analysing subdomains of orographically structured terrain (valleys and mountains), other combinations may have high probabilities of occurrence or even a different leading relationship can be observed. Consequently, no general statement for the soil moisture-atmosphere feedback can be made like wet soils lead to higher CAPE, lower CIN, and more precipitation at least over complex terrain and under different forcing mechanisms.

\section{Summary and conclusion}

The simulations presented in this study demonstrate that soil moisture has a considerable impact on convectionrelated parameters over complex and heterogeneous terrain for the seven analysed COPS IOPs. Soil moisture variations of $\pm 25 \%$ can lead to precipitation changes larger than $+500 \%$ in the region of a low mountain range or up to $-57 \%$ in the whole COPS domain, including two mountain ranges and the Rhine valley ( $\sim$ $205 \times 190 \mathrm{~km}^{2}$ ). In the wet experiments, surface fluxes produce moister and cooler boundary layers with increased equivalent potential temperatures, and lowered mean LCL and LFC. This systematic behaviour is independent of the location and even of the synoptic controls. Additionally, the potential for thunderstorms is higher in the wet experiment. This finding is also supported by a lower CCL in the wet experiment causing deeper clouds and a reduction of the lifted index, which is indicative of the severity of thunderstorms. The assumption of dry soils producing lower CAPE values than wet soils is not valid for all control areas and cases analysed and, hence, cannot be generalised, at least over complex terrain. However, most of the mean CAPE values increased with increasing initial soil moisture and the classification into four possible combinations of CAPE/CIN modifications shows a maximum for increased CAPE values with reduced CIN. The fact that this trend is not observed in all locations is of particular relevance to high-resolution forecasts. 
Regional analysis of precipitation change due to soil moisture variations revealed that in the orographically structured and heterogeneous terrain no regions can be identified which are more sensitive to soil moisture than others. A considerable, but not systematic dependence of convective precipitation on soil moisture was found for the precipitation sums of four control areas. The complexity of the soil moisture-atmosphere feedback is also reflected by the existence of a systematic relationship for a number of analysed variables, while for others (e.g. net radiation, CIN) no systematic relation was found. Obviously, the mechanisms to initiate convective storms over complex terrain are nonlinear and only partly controlled by surface conditions. One reason could be the non-systematic dependence of CIN on soil moisture, because CIN is assumed to be a factor controlling convective precipitation. It is also found that the impact of soil moisture is not systematically higher for PBL-driven regimes than for synoptic-scale forcing mechanisms, at least for the seven IOPs analysed in this study. Finally, it was found that the influence of increasing soil moisture remains small when the soils are quite wet already.

The high, but non-systematic sensitivity of precipitation to soil moisture over complex terrain demonstrates the particular importance of initial soil moisture fields in numerical weather prediction models. A realistic representation of soil moisture in these models can improve quantitative precipitation forecast. Therefore, the impact of observed soil moisture on the quality of precipitation forecasts in the COPS region will be analysed in a next step. In addition, the triggering of convection caused by soil moisture patterns could be examined by analysing convection initiation events along domain edges where soil moisture gradients occur. A separation between convective and stratiform precipitation based on the horizontal structure (granularity and intensity) of precipitation systems (e. g. STEINER et al., 1995) may be used to examine the sensitivity of different types of precipitation to soil moisture.

\section{Acknowledgments}

The authors wish to thank the Deutsche Forschungsgemeinschaft (DFG) for funding the Priority Programme SPP 1167, in which both, this study (research grant KO 924/9-1) and the COPS field campaign were embedded. We also thank the Deutscher Wetterdienst (DWD) for providing the COSMO model code as well as initial and boundary data.

\section{References}

Ács, F., A. Horváth, H. Breuer, F. Rubel, 2010: Effect of soil hydraulic parameters on the local convective precipitation. - Meteorol. Z. 19, 143-153.

Barthlott, C., J. W. Schipper, N. KAlthofF, B. Adler, C. Kottmeier, A. Blyth, S. Mobbs, 2010: Model representation of boundary-layer convergence triggering deep convection over complex terrain: A case study from COPS. - Atmos. Res. 95, 172-185.

Barthlott, C., R. Burton, D. Kirshbaum, K. HanLEY, E. RICHARD, J.-P. CHABOUREAU, J. TRENTMANN, B. Kern, H.-S. Bauer, T. Schwitall, C. Keil, Y. Seity, A. Gadian, A. Blyth, S. Mobbs, C. Flamant, J. HANDWERKER, 2011: Initiation of deep convection at marginal instability in an ensemble of mesoscale models: a case-study from COPS. - Quart. J. Roy. Meteor. Soc. 137, 118-136.

Chen, F., R. Avissar, 1994: The impact of land-surface heterogeneity on mesoscale heat fluxes. - J. Appl. Meteor. 33, 1323-1340.

Cheng, W. Y.Y., W.R. Cotton, 2004: Sensitivity of a cloud-resolving simulation of the genesis of a mesoscale convective system to horizontal heterogeneities in soil moisture initialization. - J. Hydrometeor. 5, 924-958.

DAi, A., K.E. Trenberth, T.R. KARL, 1999: Effects of clouds, soil moisture, precipitation, and water vapor on diurnal temperature range. - J. Climate 12, 2451-2473.

Doms, G., J. Förstner, E. Heise, H.-J. Herzog, M. RASCHENDORFER, T. REINHARDT, B. RITTER, R. Schrodin, J.-P. Schulz, G. Vogel, 2007: A description of the nonhydrostatic regional model LM, Part II: Physical Parameterization - Available online at www.cosmo-model.org.

Ek, M.B., A.A.M. Holtslag, 2004: Influence of soil moisture on boundary layer cloud development. - J. Hydrometeor. 5, 86-99.

ELTAHIR, E.A.B., J.S. PAL, 1996: Relationship between surface conditions and subsequent rainfall in convective storms. - J. Geophys. Res. 101, 237-245.

Findell, K.L., E.A.B. Eltahir, 2003: Atmospheric controls on soil moisture-boundary layer interactions. Part I: Framework development. - J. Hydrometeor. 4, 552-569.

Gantner, L., N. Kalthoff, 2010: Sensitivity of a modeled life cycle of a mesoscale convective system to soil moisture conditions over West Africa. - Quart. J. Roy. Meteor. Soc. 136, 471-482.

Hauck, C., C. Barthlott, L. Krauss, N. KalthofF, C. Kottmeier, 2011: Soil moisture variability and its influence on convective precipitation over complex terrain. - Quart. J. Roy. Meteor. Soc. 137, 42-56.

Hohenegger, C., P. Brockhaus, C. S. Bretherton, C. SCH ÄR, 2009: The soil moisture precipitation feedback in simulations with explicit and parameterized convection. - J. Climate 22, 5003-5020.

Kalthoff, N., M. Kohler, C. Barthlott, S. Mobbs, U. Corsmeier, B. Adler, K. Träumner, T. FoKen, R. Eigenmann, L. KRAuss, S. Khodayar, P. Di Girolamo, 2011: The dependence of convection-related parameters on surface and boundary-conditions over complex terrain. - Quart. J. Roy. Meteor. Soc., published online, DOI:10.1002/qj.686.

Koster, R.D., M.J. Suarez, M. Heiser, 2000: Variance and predictability of precipitation at seasonal-tointerannual timescales. - J. Hydrometeor. 1, 26-46. 
Koster, R.D., M.J. Suarez, R.W. Higgins, H.M. VAn DEN DOOL, 2003: Observational evidence that soil moisture variations affect precipitation. - Geophys. Res. Lett. 30, 1241.

Kottmeier, C., N. KAlthofF, C. BARthlott, U. Corsmeier, J. VAn Baelen, A. Behrendt, R. Behrendt, A. Blyth, R. Coulter, S. Crewell,

P. Di Girolamo, M. Dorninger, C. Flamant, T. Foken, M. Hagen, C. Hauck, H. Höller, H. Konow, M. Kunz, H. MahlKe, S. Mobbs, E. RICHARD, R. STEINACKER, T. WECKWERTH, A. Wieser, V. Wulfmeyer, 2008: Mechanisms initiating deep convection over complex terrain during COPS. - Meteorol. Z. 17, 931-948.

Krauss, L., C. Hauck, C. KotTMeier, 2010: Spatiotemporal soil moisture variability in Southwest Germany observed with a new monitoring network within the COPS domain. - Meteorol. Z. 19, 523-537.

PAL, J.S., E.A.B. ElTAhiR, 2001: Pathways relating soil moisture conditions to future summer rainfall within a model of the land-atmosphere system. - J. Climate 14, 1227-1242.

Pan, Z., E. TAKle, M. Segal, R. Turner, 1996: Influences of model parameterization schemes on the response of rainfall to soil moisture in the central United States. Mon. Wea. Rev. 124, 1786-1802.

SCHÄDLER, G., 1990: Triggering of atmospheric circulations by moisture inhomogeneities of the Earth's surface. Bound.-Layer Meteor. 51, 1-29.
SCHÄR, C., D. LÜTHI, U. BEYERLE, 1999: The soilprecipitation feedback: A process study with a regional climate model. - J. Climate 12, 722-741.

SCHÄTtler, U., G. DOMS, C. SCHRAFF, 2009: A description of the nonhydrostatic regional COSMO-model, Part VII: User's Guide. - Available online at www.cosmomodel.org.

Steiner, M., R.A. Houze JR, S. E. Yuter, 1995: Climatological characterization of three-dimensional storm structure from operational radar and rain gauge data. - J. Appl. Meteor. 34, 1978-2007.

TAYlor, C.M., D.J. PARKER, P.P. HARris, 2007: An observational case study of mesoscale atmospheric circulations induced by soil moisture. - Geophys. Res. Lett. 34.

Williams, E., N. RenNo, 1993: An analysis of the conditional instability of the tropical atmosphere. - Mon. Wea. Rev. 121, 21-36.

WUlfMEYER, V., A. BeHREndT, H.-S. BAUER, C. Kottmeier, U. Corsmeier, A. Blyth, G. Craig, U. Schumann, M. Hagen, S. Crewell, P. Di Girolamo, C. Flamant, M. Miller, A. Montani, S. Mobbs, E. Richard, M. Rotach, M. ARPAGAus, H. RusschenberG, P. SCHLÜSSEl, M. KÖNIG, V. GÄrTnER, R. STEINACKER, M. DORNINGER, D. Turner, T. Weckwerth, A. Hense, C. Simmer, 2008: The Convective and Orographically-induced Precipitation Study: A Research and Development Project of the World Weather Research Program for improving quantitative precipitation forecasting in low-mountain regions. - Bull. Amer. Meteor. Soc. 89, 1477-1486. 